\section{EL CINE MUSICAL DE ROBERTA TORRE: UN RETRATO POSTMODERNO DE LA SICILIA DE FINALES DEL SIGLO XX}

\author{
Eduardo Viñuela \\ Universidad de Oviedo \\ vinuelaeduardo@uniovi.es
}

\section{ROBERTA TORRES' MUSICAL FILMS: A POSTMODERN PICTURE OF SICILY AT THE END OF THE 2OTH CENTURY}

RESUMEN: A finales del siglo XX el cine musical renovó su lenguaje, dando lugar a nuevas narrativas en las que la intertextualidad y la parodia permitían nuevas significaciones y múltiples lecturas. Roberta Torre se erige en una figura representativa del cine musical contemporáneo en Italia, y en sus películas Tano da morire (1997) y Sud side story (2000) nos presenta el retrato de una Sicilia en proceso de cambio y negociación entre tradición y modernidad. La alusión a los tópicos y a los estereotipos que configuran el imaginario de la Italia meridional (mafia, inmigración, religión, música popular, etc.) dentro de una narrativa postmoderna ofrece una visión diferente que desmonta los clichés tradicionalmente asociados con Sicilia.

PALABRAS CLAVE: Cine musical, Sicilia, Italia, norte, sur.

\begin{abstract}
The renewal of the language of the musical at the turn of the century allowed for the development of new narratives in cinema through intertextualilty and parody. In Tano da morire (1997) and Sud side story (2000) Roberta Torre depicts a Sicily caught up in a process of transformation between tradition and modernity. Allusion to some of the stereotypes and clichés about southern Italy (the mafia, immigration, religion, popular music, etc.) using a postmodern narrative offers us a fresh view of Sicily, far from the traditional platitudes.
\end{abstract}

KEY WORDS: Cinema, musical, Sicily, Italy, north, south.
INTRODUCCIÓN: SEÑAS DE IDENTIDAD DEL CINE ITALIANO

En los últimos años se han multiplicado los estudios que analizan los cambios experimentados por la producción audiovisual, enfatizando el papel de las nuevas tecnologías de producción, distribución y consumo, así como los procesos de concentración y la sinergia entre los sectores que configuran este mercado. Sin embargo, parece que la transformación de este panorama atañe más a cuestiones de formatos y organización empresarial que al contenido de los productos audiovisuales. De este modo, en la actualidad el mundo cinematográfico sigue respondiendo a la estructura de géneros (drama, comedia, musical, etc.), continúa utilizando la popularidad de actores y actrices como reclamo publicitario y apelando a la "genialidad" de un director como garantía de calidad del filme.

Los cambios apuntados en la producción audiovisual suelen ser relacionados con un "nuevo escenario" de- rivado de los procesos de hibridación, globalización y glocalización, términos que preconizan la rápida transformación de la producción cultural y la pérdida de las señas de identidad nacionales y locales en favor de una cultural transnacional representada en música, cine, literatura, etc. Sin embargo, cuando nos preguntamos sobre los rasgos del cine de un determinado país observamos una serie de constantes que se resisten a los cambios radicales que se anuncian al estudiar la tecnología y la industria, y que más bien se rearticulan adaptándose a la realidad del contexto político y social en el que se crean. Al igual que sucede con el caso español, ${ }^{1}$ cuando nos centramos en la producción cultural italiana podemos apreciar una serie de caracteristicas que responden a la idiosincrasia de este país. De este modo, en uno de los últimos estudios publicados sobre cine italiano, Italian Cinema (2005), Mary P. Wood realiza un recorrido histórico en el que se puede comprobar la constante presencia de tres rasgos identitarios de la producción 
cinematográfica italiana desde sus primeros años hasta la actualidad. Por un lado, el marcado regionalismo existente en una nación joven (unificada en 1861) se plasma en el cine desde las primeras películas por medio de los diferentes acentos de los personajes, el reflejo de costumbres y tradiciones arraigadas a determinadas áreas, la inclusión de músicas populares de distintas regiones, etc., aspectos que continúan siendo habituales en las películas de directores como Giussepe Tornatore y su vinculación con Sicilia o Roberto Benigni con la Toscana. Otro de los rasgos identitarios del cine italiano es el arraigo con el presente; desde los comienzos del cine la actualidad ha sido uno de los puntos de interés, y gran parte de las películas están cargadas de referencias al momento en el que se producen, incluso cuando se trata de cine histórico ambientado en otras épocas. Por último, se observa una tendencia al pintoresquismo, se recurre mucho a los tópicos que a nivel internacional identifican con "lo italiano", especialmente en la elección de determinados monumentos urbanos mundialmente reconocibles o paisajes mediterráneos fácilmente asociables a este pais. Este pintoresquismo se refuerza muchas veces a nivel técnico, como sucede en el tratamiento de la luz en Senso (Visconti, 1954), Belleza Robada (Bertolucci, 1996) o Cinema Paradiso (Tornatore, 2002).

Estas tres constantes que se repiten en el cine italiano desde sus comienzos podemos reconocerlas fácilmente en Tano da morire (1997) y Sud side story (2000), dos películas musicales de Roberta Torre ambientadas y rodadas en la ciudad de Palermo que revisitan los tópicos asociados tradicionalmente con Sicilia, incluyendo temáticas de gran actualidad en la sociedad italiana, como la inmigración norteafricana en la isla. Sin embargo, a través de la ruptura con las convenciones formales y estéticas del cine musical clásico, Torre consigue resignificar las tramas, los lugares y los personajes que aparecen en estas películas a través de la parodia y el pastiche postmoderno, adoptando un punto de vista crítico que ofrece una visión poliédrica de la Sicilia del momento, plasmando la continua dialéctica entre la realidad cotidiana y la construcción mediada del sur de Italia. Así, la novedad en el cine musical de Roberta Torre la encontramos en la rearticulación de los elementos tradicionales del imaginario siciliano con un lenguaje audiovisual propio forjado en la experimentación que caracterizó a los jóvenes cineastas formados en los años ochenta y noventa.

\section{ROBERTA TORRE Y LA GENERACIÓN DE LOS AÑOS OCHENTA}

Los años ochenta han pasado a la historia del cine italiano como una época de crisis a diferentes niveles. La proyección internacional alcanzada en las décadas anteriores de la mano de directores como Fellini, Passolini, Visconti o Leone deja paso a un escenario en el que solo algunas producciones de autores consagrados en décadas anteriores consiguen cierta notoriedad internacional, como Érase una vez en América (Leone, 1984) o El último emperador (Bertolucci, 1987). Por otra parte, la afluencia de público a las salas de cine desciende considerablemente desde finales de los años setenta debido al auge de la televisión y el vídeo (Monteleone, 2004, 88), lo que provoca que se desmantelen las grandes salas de cine en las ciudades importantes sin recurrir al formato de multisalas, así como el cierre progresivo de las salas pequeñas y de las emplazadas en la periferia de las ciudades o en núcleos suburbanos. Esto afecta a las prácticas de consumo cultural ligadas al ocio, la población italiana pierde la costumbre de ir al cine y durante los años ochenta se inclina por el cine norteamericano en detrimento del producto nacional. ${ }^{2}$

Los "grandes nombres" y "genios" del cine italiano de los años 1950-70 se diluyen, y los autores de los años ochenta son más bien realizadores audiovisuales con referentes audiovisuales eclécticos, sin el apoyo de productores que apuesten por una línea estética o temática definida ni de críticos que defiendan sus obras; carecen, asimismo, de infraestructuras de producción centralizadas. Como señala Brunetta, "el cambio generacional significa también la transformación de las formas de producción, de las amistades, de las políticas individuales y de grupo, de las estrategias de producción, de las temáticas, de los estilos" ${ }^{\prime 3}$ (Brunetta, 1998, 521).

La nueva generación de directores italianos, en la que encontramos a Nanni Moretti, Marco Risi, Cinzia Th. Torrini o Francesca Archibugi, conecta con la realidad italiana del momento y se centra en las relaciones interpersonales y los sentimientos individuales de los personajes, poniendo énfasis en el trabajo de guión. Sus películas se ajustan a bajos presupuestos y su actividad muchas veces está relacionada con la televisión. Resulta significativa la actividad desarrollada durante esta década en la escuela de cine Ipotesi Cinema, fundada por el director Ermanno $\mathrm{Olmi}^{4} \mathrm{y}$ 
el productor y crítico cinematográfico Paolo Valmarana en Bassano del Grappa en 1982. El objetivo de esta escuela es apoyar y formar a los jóvenes directores del cine italiano a través de la producción de cortometrajes en los que, además de la dirección, se ocupan del guión y del montaje, dando como resultado un filme en el que poder desarrollar un lenguaje personal. En la escuela de Bassano se favorece la realización de proyectos que conecten con la realidad social del momento y con un estilo de narración opaca, en la que el director no se posiciona ante los hechos que narra y obliga al espectador a construir su propio discurso con lo que está viendo.

Este cambio de generación supuso también la incorporación generalizada de las mujeres a la dirección cinematográfica en Italia. Hasta entonces las directoras italianas habian sido una excepción a la norma, con pioneras del cine mudo como Elvira Notari o figuras del cine de los años sesenta y setenta como Liliana Cavani o Lina Wertmüller. Esta realidad había sido reflejada en la obra Kinomata: $L a$ donna nel cinema (1980), que recoge el papel subordinado de las mujeres en la historia del cine y aboga por una mayor presencia femenina en puestos de responsabilidad como la dirección. Desde entonces el número de directoras en el cine italiano se ha incrementado de forma paulatina y en la actualidad contamos con un buen número de realizadoras con una trayectoria consolidada. ${ }^{5}$

En este contexto desarrolla su actividad Roberta Torre, cineasta nacida en Milán en 1962, que estudia en la escuela de cine de esta ciudad y más tarde en Ipotesi Cinema, donde realiza sus primeros cortometrajes. En 1991 se traslada a Palermo, donde continúa su producción en formato vídeo y se involucra en varios proyectos para apoyar la creación audiovisual en Sicilia, como la productora Anonimi \& Independenti, la sección de vídeo del Festival Palermocinema (1993) o del concurso de obras videográficas Trenta secondi dalla fine. A finales de los años noventa comienza su actividad en el mundo del cine, dirigiendo los dos largometrajes musicales que analizamos en este artículo. Su carrera se ha consolidado en los últimos años con la creación de la productora Rosettafilm en 2008 y la dirección de varios largometrajes: Angela (2002), Mare nero (2006) o I baci mai dati (2010), una filmografía que demuestra la versatilidad de la directora para desenvolverse en diferentes géneros (musical, thriller, documental, drama) abordando una serie de temáticas que son constantes en su carrera, como los derechos humanos, la violencia hacia las mujeres o el mundo de la mafia.

\section{HaCia UNA REDEFINICIÓN DEL MUSICAL EN EL CINE CONTEMPORÁNEO}

El cine musical ha evolucionado paulatinamente desde sus inicios con la llegada del sonoro en los años veinte. De la mera transposición de elementos del teatro musical de Broadway se pasó al desarrollo de un lenguaje audiovisual propio que podemos observar ya en las coreografías de Bubsby Berkeley para varias películas de los años treinta. En las décadas posteriores se probaron soluciones para integrar el número musical dentro de la trama narrativa sin perder el atractivo de los números musicales; en este sentido, John Mundy señala que "el éxito del musical y su popularidad entre los espectadores de los años treinta y cuarenta dependía de la fusión formal, temática e ideológica de espectáculo y narrativa" (Mundy, 1999, 75). Este género cinematográfico siguió evolucionando en las décadas posteriores con la inclusión de diferentes géneros de música popular urbana y el propio desarrollo del lenguaje cinematográfico.

Sin embargo, no podemos pasar por alto el auge y la renovación formal del cine musical en el cambio de siglo, período en el que se engloban las películas de Roberta Torre. Teresa Fraile aborda este fenómeno y apunta que "las películas de lo que llamamos el cine musical contemporáneo son reflejo de una tendencia cercana al postmodernismo, de la reutilización de géneros cinematográficos reconstruidos y de la mezcla de registros" (Fraile, 2010, 158). Esta autora sitúa dentro del musical contemporáneo a películas como Dancer in the Dark (1999), Moulin Rouge (2001) o las españolas El otro lado de la cama (2002) y Los dos lados de la cama (2005), destacando una serie de características que comparten en gran medida todas ellas. Siguiendo algunos de los aspectos estéticos y formales que señala Fraile, es posible enmarcar las películas Tano da morire y Sud side story dentro del cine musical contemporáneo italiano.

Al igual que sucede con muchas de las películas musicales, el argumento de estos filmes sigue una línea narrativa sencilla, centrada en una trama principal en la que participan 
diferentes personajes. En Tano da morire el asesinato de Tano Guarrasi, uno de los capos de la mafia en el barrio de la Vucciria de Palermo, sirve para narrar la historia de este personaje y de su familia (sus hermanas y su hija). A través del desarrollo de los personajes cercanos a Tano vamos conociendo su vida, su personalidad y las razones de su muerte. Todo ello se desarrolla con una estructura que intercala números musicales interpretados por los habitantes del barrio y que finaliza con un número musical coral en el que participan varios comerciantes del mercado de la Vucciria. Por su parte, Sud side story es una reescritura de Romeo y Julieta, una historia de amor entre Tony Giuletto, joven cantante sin éxito que vive en casa de sus tías en Palermo, y Romea Wacombo, inmigrante ilegal nigeriana que ejerce la prostitución en la ciudad. La trama principal sigue la estructura de la obra de Shakespeare, aunque la adaptación a la realidad de Palermo a finales del siglo XX sirve para incluir críticas al racismo existente en la Italia contemporánea y al trato dispensado a los inmigrantes ilegales. Como podemos observar, la estructura narrativa de estas películas no presenta variaciones significativas con respecto al musical clásico de Hollywood, lo que permite al espectador identificar este género cinematográfico en pocas escenas; sin embargo, la estética y la forma de hacer avanzar la acción se aleja deliberadamente de lo convencional, dando lugar a una renovación del género.

\section{LAS RELACIONES INTERTEXTUALES COMO ESTRATEGIA DE RESIGNIFICACIÓN}

Uno de los aspectos que destacan dentro del musical contemporáneo es la alusión a modelos anteriores dentro del propio género, estrategia que cuenta con la competencia de los espectadores, conocedores de las convenciones establecidas durante décadas; de esta forma podemos hablar de un "metamusical" (Fraile, 2010, 143) que establece relaciones intertextuales con películas anteriores y utiliza diversos pastiches, construyendo un producto postmoderno. En Tano da morire la presentación del protagonista en las primeras escenas de la película se produce en una escena que recuerda a West Side Story (1961), con una coreografía en la que Tano sale en defensa de sus hermanas, que habian sido increpadas por un grupo de hombres. Los prolegómenos de la pelea se acompañan de un chasquido de dedos que marca el pulso musical de la escena de forma similar a la pelea entre los Jets y los Sharks en el musical americano, lo que genera una tensión y una expectativa reforzada por el uso de la música de piano y las miradas de desafío entre los contrincantes. La intertextualidad con la escena de West Side Story se refuerza con el estilo de la vestimenta de los personajes masculinos, los peinados, sus gestos y la "coreografía" de la pelea. Esta escena se construye como una parodia de las peleas que tienen lugar en el musical de Robert Wise, tanto por la deliberada inverosimilitud de los golpes de la pelea, que se refuerzan con sonidos de golpes propios del mundo del cómic, como por la reacción exagerada y estereotipada de las hermanas de Tano ante la pelea, con varios gritos y gestos acompasados y al unísono.

Como señala Millicent Marcus, revelando el artificio de la comedia musical esta película no solo introduce innovaciones dentro del género cinematográfico, sino que además ofrece una imagen diferente de la mafia, dando lugar a una renovación en el imaginario establecido de esta institución (Marcus, 2002, 234). No en vano Tano da morire ha sido promocionada como "el primer musical sobre la mafia"; esto evidencia la voluntad de Torre de ofrecer una visión diferente de la mafia, ya que a priori no parece un género adecuado para representar a esta organización. De hecho, la directora se vale del imaginario creado en torno a la mafia a través de su representación en numerosos formatos audiovisuales y en películas de culto, como la trilogía de El padrino, para jugar con los estereotipos y convertirlos en pastiches postmodernos que ofrezcan nuevas posibilidades de significación. El momento en el que Tano se inicia en la mafia se representa nuevamente a través del número musical, Simma Mafia (Somos la Mafia), una canción disco que sigue los patrones estilísticos de la música de baile de los años setenta y que da lugar a una escena con claras alusiones a la película Fiebre del sábado noche (1977). Tano aparece bailando en una discoteca ambientada con luces de colores rebotadas en espejos y rodeado de un grupo de bailarines masculinos vestidos con camisas ajustadas de colores vivos y prendas de terciopelo. La coreografía, en la que Tano ostenta el protagonismo, combina los pasos de baile propios de la música disco con las insinuaciones y los gestos del cabaret (guiños, besos, poses). Así, el protocolo de los ritos de iniciación en la mafia se exageran hasta rozar lo grotesco y se resignifican en el contexto de un espectáculo de baile kitsch. En este sentido, esta representación de la mafia puede ser leída como una crí- 
tica a los tópicos alejados de la realidad en torno a esta organización; en palabras de Roberta Torre, "mi propósito era cuestionar el sistema de valores de la mafia, que suele representarse en un mismo sentido. Lo interesante es que los Ilamados filmes sobre la mafia tienden a dar crédito a estas representaciones" (Torre en Marcus, 2002, 236).

La alusión a West Side Story se hace más patente en la película Sud side story, partiendo del propio título, que si en el musical americano hacía referencia al West side neoyorkino en el que se desarrollaba la acción, una de las zonas con mayor concentración de población inmigrante de la ciudad, en la película de Torre alude al sur de Italia como lugar de recepción de inmigrantes africanos y sitúa la trama en un barrio popular de la ciudad de Palermo. Al mismo tiempo, ambas películas tienen como referente a Romeo y Julieta de Shakespeare, que actúa como obra seminal de cantidad de argumentos desarrollados en diferentes medios de expresión. No en vano, dentro del cine musical encontramos la película Romeo + Juliet (1996), un claro exponente de la renovación del musical contemporáneo en la que se mantiene el texto original de Shakespeare mientras que la acción se ambienta en el presente. Roberta Torre no se limita a un aggionamento del argumento de la obra teatral, sino que altera el sexo de los protagonistas sin alterar su rol de género. Así, el papel de Romeo pasa a ser interpretado por Romea, que camina por las calles de Palermo, toma la iniciativa en la relación amorosa y encarna la determinación del personaje masculino en la obra de Shakespeare, y el de Julieta por Tony Giuletto, personaje recluido en casa de sus tías, rodeado de iconos y fetiches del rock and roll americano de los años cincuenta y sesenta, y con el sueño de convertirse en una estrella de rock; en definitiva, un personaje que encarna la pasividad que representa Julieta en el original, esperando en el balcón de su casa la llegada de su amado. Las referencias a esta obra son constantes a lo largo de todo el filme y se recrea la iconografía de algunos de sus pasajes más representativos, como la escena del balcón o la muerte de los protagonistas, ambos momentos acompañados del tema musical de amor, que funciona como leitmotiv a lo largo de toda la película.

La admiración que Tony Giuletto siente por los EE.UU. se construye y se manifiesta a través de su veneración hacia los iconos de la cultura popular norteamericana de mediados de siglo XX. De hecho, la relación que establece este personaje con estos fetiches ayuda al espectador a cono- cer su personalidad y sus ansias por alcanzar un mundo que no existe pero que él ha recreado en su habitación, una estancia amueblada con mobiliario kitsch y luces de colores en la que aparecen imágenes de iconos pop como Marilyn Monroe, Elvis Preisley, Little Tony; ${ }_{i}^{6}$ un ambiente en sintonía con su imagen, que trata de emular a los dos últimos. Tony Giuletto es un personaje que no tiene diálogo dentro del filme y que solo se expresa a través de sus canciones, por lo que la relación intertextual que establece con estos cantantes cobra mayor relevancia para comprender su forma de pensar. Por otra parte, el mundo de pastiches en el que Roberta Torre sitúa a Tony tiene una clara intención postmoderna que da lugar a un anacronismo con el tiempo histórico en el que se desarrolla el filme y crea un contrapunto entre el glamour de la cultura pop estadounidense y la realidad cotidiana del barrio de Palermo en el que vive Tony. Esta intención se evidencia en el primer número musical cantado por Tony, en el que él mismo nos cuenta su historia. La canción está precedida de una escena en la que las tres tías, sentadas en una sala decorada de forma tradicional, nos informan de su intención de casar a su sobrino con Maria, una vecina del barrio. Acto seguido, aparece Tony en su habitación rodeado de sus iconos y cantando una canción pseudodeclamada en la que habla tanto de sus orígenes como de sus sueños de triunfar en el mundo de la música y viajar a EE.UU. La canción se interrumpe varias veces para incluir escenas en las que las tías y otras mujeres del barrio complementan la historia de Tony y desarrollan una coreografía en la calle, lo que impide al espectador introducirse plenamente en el mundo de fantasía del protagonista.

Los fetiches de Tony forman parte de su iconografía, y le acompañan no solo en su habitación y en sus sueños, sino también en su "lecho de muerte", en el que observamos una escenografía nuevamente llena de contrastes. La escena se desarrolla en la habitación del protagonista, que aparece tumbado con luces de colores al cuello y rodeado de las imágenes de Elvis Presley, Marilyn Monroe y Little Tony; un ambiente que se contrapone a los llantos exagerados de sus tres tías, vestidas de riguroso luto y lamentándose por la muerte de su sobrino. ${ }^{7}$ La relación que Tony establece con sus ídolos va más allá de la admiración icónica, y dentro de su mundo de fantasía dialoga con una de sus estrellas admiradas, Little Tony (un papel interpretado por el propio cantante). Este artista da consejos al protagonista en su relación con Romea, actúa de deux ex maquina en

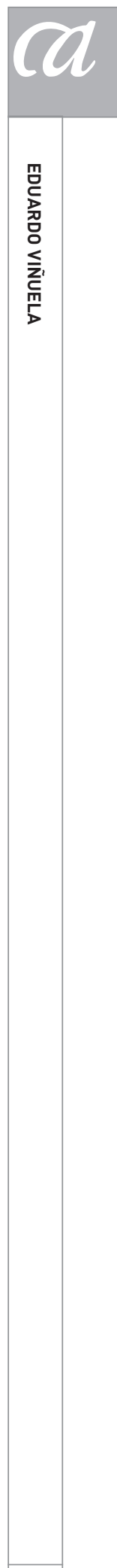

1079 
algunas situaciones para facilitar la relación entre Romea y Tony e interpreta algunas de sus canciones más famosas, como Ragazzo col ciuffo (1962) o Riderá (1966), a modo de consejo sentimental. De esta forma, se incluyen canciones del pasado otorgándoles un nuevo significado en la diégesis fílmica; un aspecto significativo si tenemos en cuenta que "el uso de canciones pop reinterpretadas, adaptadas, orquestadas, se ha convertido en una práctica habitual y marca de fábrica del musical contemporáneo" (Fraile, 2010, 144).

El empleo de pastiches postmodernos y las relaciones intertextuales que hemos señalado se ven favorecidas por la mezcla de formatos audiovisuales en ambas películas, lo que dificulta la linealidad del filme y aumenta la sensación de fragmentación narrativa, característica postmoderna vinculada por muchos autores a formatos como el videoclip (Viñuela, 2009, 34). Si bien el cine musical es un género que se presta fácilmente a la experimentación narrativa y a la mezcla de formatos, en las películas de Torre este aspecto se lleva al extremo y vemos imágenes que parecen extraídas de documentales que se intercalan con números rodados siguiendo los patrones de vídeos musicales, imágenes de baja resolución habituales de la televisión y escenas en las que se simula una conexión en directo dentro de un informativo televisivo. Además, los medios de comunicación forman parte de la propia trama, como sucede cuando Romea conoce la muerte de Tony a través de los periódicos, que se hacen eco de la noticia.

Roberta Torre utiliza esta mezcla de formatos como un medio para hacer más presente a los diferentes medios de representación a través de los cuales se construye y se difunde un determinado imaginario del sur de Italia, en especial todo lo relacionado con la mafia. Así, la muerte de Tano la presenta un periodista (Máximo Pullara) como si se tratara de un informativo en el que el periodista narra los hechos y trata de recoger algunas opiniones de los presentes en el lugar del asesinato, que son personajes de la película. Del mismo modo, el desenlace de Sud side story altera la resolución de la obra se Shakespeare e incluye un ingrediente de venganza muy acorde con las prácticas relacionadas con la mafia, de manera que Tony y sus tres tías son acribilladas por los ayudantes de la maga blanca, a la que el joven había robado para comprar la poción que le haría parecer muerto. Tras la masacre, vemos la llegada de la televisión y la crónica periodística de los hechos a cargo del periodista Mario Azzolini. Como podemos observar, en ambos casos aparecen periodistas que desempeñan esta labor en la vida real, Pullara del Telegiornale di Sicilia (TGS) y Azzolini de la RAI1 en Sicilia, lo que aumenta la veracidad de la representación y facilita la lectura crítica acerca de la forma en la que los asesinatos son narrados a través de los medios de comunicación.

\section{ESTEREOTIPOS EN TORNO A LAS RELACIONES NORTE-SUR}

La unificación de Italia aglutina bajo un mismo Estado regiones muy distantes entre sí, tanto en lo geográfico como en lo cultural. La distinta evolución de las regiones que en la actualidad configuran el pais ha marcado la distancia entre el norte y el sur, un proceso que se ha fraguado a lo largo de varios siglos y que se acelera en el siglo XIX con la creación del Reino de las Dos Sicilias (1816-1861), que se extendía por todo el sur de la península itálica y que estaba bajo el control de la Casa de Borbón española, y el dominio del Imperio Austrohúngaro sobre la zona norte; en el centro peninsular quedaba una amplia región que conformaban los Estados Vaticanos. A pesar de que la unificación en 1861 fortaleció las relaciones entre las distintas regiones, el contacto con diferentes potencias europeas como Francia o Austria procuró un mayor desarrollo económico al norte del pais que se vio potenciado con la segunda revolución industrial, mientras que la Italia meridional mantenía una economía rural y una estructura politica que conservaba vestigios del sistema absolutista que había caracterizado al Reino de las Dos Sicilias.

Desde entonces las diferencias entre el norte y el sur del país han estado siempre patentes y han sido plasmadas en literatura, teatro, música y cine. En este sentido, podemos destacar la película Rocco y sus hermanos (Visconti, 1960), en la que se narran los problemas de una familia del sur de Italia que se ve obligada a emigrar hacia el norte industrializado (Milán) para escapar de la pobreza. Al mismo tiempo, encontramos otras películas que ofrecen una cara más amable, con tintes nostálgicos, del sur de Italia, y que suelen situar la acción en Sicilia, es el caso de El gatopardo (Visconti, 1963), Malena (Tornatore, 2000) e incluso la primera entrega de El padrino (Coppola, 1972). Estas películas han contribuido a construir el imaginario de la Italia meridional, una serie de tópicos con los que juega en clave de 
comedia el cine italiano de los últimos años, como sucede en los musicales de Roberta Torre o el reciente estreno de Bienvenidos al sur (Miniero, 2010), remake de la comedia francesa Bienvenidos al norte (Boon, 2008).

La dialéctica norte-sur la encontramos en la propia Roberta Torre, una directora que va a contracorriente y se traslada desde su Milán natal a Sicilia para desarrollar su carrera. El contacto con la realidad de Palermo gracias a sus trabajos en vídeo durante los años noventa le permite a esta directora tomar conciencia de cómo se construyen los clichés que identifican el sur de Italia, un aspecto que se plasma claramente en sus dos primeros largometrajes. Torre plantea una narración en la que combina los clichés sureños presentados de forma exagerada y grotesca con elementos totalmente alejados de los tópicos que podríamos calificar de hiperreales. El número musical que presenta a Tony Giuletto es un claro exponente de esta mezcla de elementos en Sud side story, ya que la autobiografía mitificada que nos canta Tony tiene poco que ver con la versión de las tías que se va intercalando en la canción; en Tano da morire lo observamos en las escenas en las que las donne $d^{\prime}$ 'onore ${ }^{8}$ (las esposas de los capos locales de la mafia) aparecen en la peluquería preparándose para acudir a la boda de Franca, una de las hermanas de Tano. El glamour y la sofisticación que suele caracterizar a las mujeres de la mafia en otras películas se deconstruye aquí presentando mujeres gordas, con un maquillaje exagerado, conversando en tono elevado con un marcado acento siciliano y vestidas con ropas comunes y de colores llamativos, características que se corresponden con el fenotipo de mujeres de un barrio popular del sur de Italia. Este aspecto está en sintonía con las corrientes de renovación del cine musical a finales del siglo $X X$, en el que los musicales no solo presentan mundos ideales perfectamente diseñados para la narración y la puesta en escena, como solía suceder en los modelos clásicos, sino que incluye aspectos de la vida cotidiana que rompen la "magia" que caracterizaba a este género cinematográfico. En sintonía con este aspecto, y al igual que sucede en otros musicales contemporáneos (Moulin rouge, El otro lado de la cama...), en las películas de Torre son los propios actores los que cantan en los números musicales, unos actores que, por otra parte, no son profesionales, sino vecinos del barrio de la Vicciria de Palermo, lo que en última instancia refuerza la verosimilitud y el carácter amateur de estas producciones y se distancian claramente de los estándares del género.
Uno de los aspectos que más aparece en el imaginario del sur de Italia, y especialmente en Sicilia, es la actividad de la mafia. Esto sucede no solo dentro de Italia, sino a nivel internacional, ya que la zona meridional de Italia es representada como la cuna de la mayor parte de mafias en películas y series de televisión norteamericanas (El padrino, Uno de los nuestros, Los Soprano). Por esta razón, Roberta Torre centra su primer largometraje (Tano da morire) en la imagen estereotipada que se ofrece de esta organización, construida a través de la representación de ritos popularizados y sobredimensionados en el imaginario de la mafia. Torre no renuncia a incluir estos tópicos en su película, pero al presentarlos inmersos en una narrativa tan bizarra como la que presenta este filme consigue una resemantización que evidencia lo absurdo del estereotipo. Esto sucede en la escena en la que los diferentes personajes cercanos a Tano (su hija, sus hermanas, sus colaboradores, etc.) descubren su cuerpo momentos después de ser asesinado. Los personajes van entrando en la tienda uno a uno, contribuyendo al llanto coral y profiriendo gritos de lamento por lo sucedido; esto va aumentando el dramatismo de la escena, que se prolonga durante más de dos minutos, lo que pone de manifiesto el artificio y la puesta en escena de este tipo de expresiones de dolor que suelen achacarse al "carácter latino" y a la fuerza de los lazos afectivos dentro de la familia en el sur de Italia.

Otros ritos se corresponden tan fielmente con el imaginario establecido de la mafia que invitan a una lectura en clave de parodia. Así, tras el asesinato de Tano, Torre nos muestra una reunión de cinco hombres en una habitación sobria, vestidos con traje negro y sombrero y sentados con actitud hierática en torno a una mesa en la que hay una vela encendida. Uno de ellos apaga la vela para simbolizar la muerte de Tano. La imagen corresponde al estereotipo de una reunión tradicional de capos de la mafia para dar el último adiós a uno de los miembros de "la familia", y además connota unos valores de tradición que presuponen un origen ancestral a esta organización. En otra escena vemos una sucesión de primeros planos de hombres viejos que se tapan la boca, los ojos y los oídos de forma alternativa, poniendo en imágenes el lema de la mafia "no veo, no escucho, no hablo" en relación al hermetismo de esta institución y a la complicidad de muchos de los ciudadanos.

En Sud side story Torre aborda el racismo, un tema de actualidad en Italia, que sirve para poner de relieve los pre- 
juicios de muchos italianos hacia los inmigrantes africanos y explicar este fenómeno como una consecuencia del rechazo a la otredad. La llegada de un grupo de inmigrantes africanas a la calle en la que viven Tony y sus tías altera la vida cotidiana del barrio; éstas se presentan diciendo "hemos llegado ahora de África", lo que provoca el horror entre los habitantes locales; acto seguido comienza un número musical en el que las africanas cuentan su periplo hasta llegar a Palermo. En varias ocasiones a lo largo del filme las tías de Tony, asustadas ante la presencia de la otredad desconocida dentro de su barrio, hablan de estas inmigrantes en términos racistas: "negras feas", "caníbales", "simias", etc. Roberta Torre no se limita a plasmar el racismo de las tías de Tano hacia las inmigrantes, sino que contrapone su visión de las africanas con la que éstas tienen de los italianos. Las inmigrantes se lamentan de estar en un lugar lleno de "gente gorda", de "monstruos" que comen "pasta continuamente", mientras las tías de Tano en cambio dicen que las africanas "comen plátanos", "huelen mal" y "no se lavan", una serie de calificativos despreciativos que se alternan en la misma escena, dejando patente la falta de comunicación interracial y lo peligroso de establecer juicios de valor en torno a ideas preconcebidas y normalizadas.

La oposición entre las tías de Tony y las amigas de Romea en clave racial es una actualización del odio entre las familias Montesco y Capuleto en la obra de Shakespeare $y$, en consecuencia, se hace aún mayor ante el enamoramiento de Romea y Giuletto. Si las tías de Tony se oponen al amor de su sobrino hacia Romea, las amigas de ésta no son menos y sentencian que "no es un hombre para ella". Así, el único acercamiento interracial es el que se produce entre los protagonistas, que se convierten en agentes de tolerancia e integración. Éstas son las palabras que predominan en el discurso del alcalde de la ciudad, que aparece como personaje del filme en diferentes momentos y que promueve la "campaña de la integración", dentro de la cual está prevista la proclamación de un santo negro como nuevo patrón de la ciudad de Palermo. La oposición de la población local y de la mafia da lugar a manifestaciones $y$, finalmente, a la destrucción de la estatua del santo negro, que debía salir en procesión junto a la patrona oficial de la ciudad, Santa Rosalía. Torre pone de manifiesto de esta forma la lejanía entre el discurso vacío de la política y la realidad social de la ciudad, y critica las iniciativas disparatadas y vacías de contenido que en ocasiones se promueven bajo el paraguas de la integración y la tolerancia.

La crítica se extiende a los medios de comunicación, que bajo una postura políticamente correcta construyen discursos en torno al fenómeno de la inmigración igual de vacíos que los políticos y en los que subyace un racismo latente y una tendencia a generar estados de alarma en la población. Así, en las intervenciones del periodista Mario Azzolini se habla de Romea como extracomunitaria ${ }^{9}$ o mujer "de color", términos que no aportan información relevante en las crónicas y que dejan entrever lo que podemos denominar un discurso racista políticamente correcto. Del mismo modo, al final de una de las crónicas el periodista advierte de que la tensión existente "podría desatar una nueva oleada de odio racial", lo que implícitamente contribuye a incitarla. Estos discursos fomentan otra separación entre norte y sur, pero esta vez no la existente entre los italianos de diferentes regiones, sino entre los ciudadanos italianos y los inmigrantes africanos asentados en Italia, los situados en el sud side del sur del país.

Como suele ser habitual dentro de este género cinematográfico, la música juega un papel importante en la película, no solo por determinar su estética y su estructuración formal, sino también por ser un elemento que permite tanto hacer avanzar la acción, como conocer la historia y los sentimientos de un personaje o recoger reflexiones en torno a lo que se narra. Sin embargo, en las películas musicales de Torre su función va más allá y juega un papel activo como elemento de cohesión de la identidad del sur de Italia. A pesar de tratarse de musicales sicilianos, la mayor parte de canciones italianas están cantadas en napolitano; de hecho, la música de Tano da morire está compuesta por Nino d'Angelo, un cantante napolitano muy popular en el sur del pais, lo que resulta llamativo en una película tan ligada a Palermo. El uso de este repertorio musical es consciente por parte de la directora, que considera la canción napolitana como "un lenguaje común en todo el sur [del país]" (Torre en Marcus, 2002, 244), un argumento refrendado por Patrizia Calefato, que justifica la elección de Torre como "una forma de crear una koiné lingüística representada por el napolitano" (Calefato, 2000, 120). Por su parte, Millicent Marcus establece una relación entre el cine musical de Torre y la sceneggiata ${ }_{10}{ }^{10}$ un género que continúa la diferenciada evolución de la música escénica del sur de Italia. 
La música ha reflejado siempre las diferencias sociales y culturales entre el norte y el sur del pais, un aspecto que ha quedado patente tanto en las peculiaridades estilisticas que presentaba la ópera napolitana con respecto a los patrones de esta forma musical en el norte ya en el siglo XVII, como en la diferencia entre los repertorios de música tradicional que se desarrollaron en ambas zonas. Así, el etnomusicólogo Bruno Nettl señala el escaso contacto de la música popular del sur de Italia con las corrientes musicales que circulaban por Europa, lo que ha dado lugar a una evolución diferenciada con respecto al norte, e incluso apunta una serie de indicios que relacionarían la música tradicional del sur con la música africana, por los contactos establecidos a través del Mediterráneo (Nettl, $1985,114)$. La configuración de un repertorio característico del sur de Italia se vio favorecida por la creación del Reino de las Dos Sicilias, que unificó las variantes regionales de parte del repertorio musical tradicional del sur de Italia (como sucedió con la tarantela) como un medio para reforzar las señas de identidad del nuevo reino. En la difusión de este repertorio tuvo gran importancia la grabación de canciones napolitanas interpretadas por Enrico Caruso, que eran consumidas masivamente por los italianos emigrados a EE.UU. y que pronto se convirtieron en seña de identidad del sur del pais."

La lucha entre la conservación de la tradición italiana y la hibridación cultural que plantea Sud side story ante la llegada de las inmigrantes africanas se plasma claramente en los usos de la música. La oposición a la relación entre Romea y Tony por parte de su entorno más cercano es una forma de conservar y reafirmar las señas de identidad tanto de lo italiano como de lo africano, entre las cuales se encuentra la música. Así, la tradición italiana suena a canción napolitana, mientras que lo africano, lejos de recurrir a la música tradicional de ese continente, se articula con la música popular urbana de raíz africana (rock and roll, rhythm \& blues, soul, etc.). De este modo, Torre no solo utiliza los diferentes repertorios musicales como un medio para reafirmar las señas de identidad de los personajes, sino también como un recurso para reflejar su postura a favor de una Italia que mantenga las costumbres y la moral tradicional o un país abierto a los procesos de hibridación cultural que se producen en las urbes contemporáneas; en definitiva, una oposición entre tradición y modernidad en la que el rock and roll articula el sentido de libertad que tuvo entre la juventud estadounidense de los años cin- cuenta y sesenta. La escena que mejor ilustra esta confrontación es el número musical en el que Little Tony y Mario Merota $^{12}$ se disputan el rol de consejero sentimental del protagonista. Este último recomienda a Tony una canción de amor napolitana para enamorar a Romea que él mismo interpreta a continuación; Little Tony interrumpe la canción y le dice en inglés a Tony "el rock and roll está hecho para ti", "Romea está loca por el rock and roll" e interpreta su canción II ragazzo col ciufo. La discusión entre ambos artistas deja perplejo a Tony, que finalmente se decide por su ídolo y por el rock and roll.

\section{Conclusiones}

El cine musical ha sido siempre un género cinematográfico muy propicio para la experimentación formal. Sin embargo, no es hasta la irrupción del llamado musical contemporáneo a finales del siglo XX cuando asistimos a una renovación de este formato a todos los niveles. Así, en películas como Tano da morire o Sud side story la mezcla de formatos y la narrativa postmoderna elaborada por la directora posibilitan al espectador varias lecturas del filme a través de relaciones intertextuales y alusiones a estereotipos en clave de parodia. Roberta Torre obliga a los espectadores a construir el discurso cinematográfico en base a lo que están viendo y a adoptar una actitud crítica ante la forma en la que los medios de comunicación contribuyen a reforzar estereotipos que terminan por naturalizarse, todo ello sin perder de vista algunas de las señas de identidad del cine musical, como son el entretenimiento, la abundancia de números musicales y las coreografías espectaculares.

Estas películas contribuyen a ofrecer una cara diversa del sur de Italia (y de Sicilia en particular), un área que suele aparecer representada en el cine como arraigada en la tradición, anclada en el pasado y dentro de una estética acorde con el pintoresquismo. Torre pone en evidencia lo absurdo de muchos estereotipos creados en torno a la Italia meridional y nos muestra un Palermo en proceso de transformación, que se debate entre la tradición y la modernidad, en el que cada vez es más difícil evitar cuestionarse la vigencia de una moral imperante. De este modo, en los filmes de Torre la mafia de finales del siglo XX no se rige por los códigos de honor tradicionales y ha adaptado incluso sus rituales a los tiempos actuales, de la misma 
forma que en el Palermo del siglo XXI cada vez resulta más difícil mantener las señas de identidad en base a pa- rámetros como la nacionalidad o la raza y evitar historias de amor como la de Romea y Giuletto.

\section{NOTAS}

1 Recientemente se ha publicado la obra Creación musical, cultura popular y construcción nacional (Alonso, Celsa et al, 2011), en la que se analizan los fundamentos y las constantes rearticulaciones de elementos identitarios españoles en la música (y en la producción cultural en general) de España en distintos momentos de los siglos XIX y XX.

2 Si en 1977 el 52\% de los espectadores acudia a las salas a ver cine italiano y el 33\% lo hacía para ver cine americano, en 1989 solo un 21,7\% consumía cine italiano frente a un $63 \%$ que prefería el cine norteamericano (Brunetta, 1998, 486).

3 Todas las traducciones son del autor del artículo.

4 Ermanno Olmi es uno de los grandes representantes del cine neorrealista italiano de los años sesenta, junto a Antonioni, Fellini, o Passolini. De esta forma, la escuela fundada por Olmi sirve como nexo de unión intergeneracional.

5 En el Diccionario crítico de directoras de cine europeas (Rodríguez Fernández, 2011) aparecen recogidas más de un centenar de directoras de cine italiano, de las cuales, más de un ochenta por ciento han desarrollado su actividad a partir de los años ochenta.

6 Nombre artístico de Antonio Ciacci (1941), uno de los mayores exponentes de la canción moderna en Italia durante los años sesenta.

Fecha de recepción: 6 de mayo Fecha de admisión: 30 de mayo funerales tradicionales de la Europa meridional.

8 "Mujeres de honor" guarda relación con el término "hombres de honor", que incluye a los integrantes de una estructura mafiosa.

9 Término que se utiliza comúnmente en los medios de comunicación italianos para referirse a los extranjeros que pertenecen a paises que no forman parte de la Unión Europea.

10 La sceneggiata es un tipo de espectáculo escénico que combina música, teatro y baile en el que se representa una breve acción teatral basada en el argumento de una canción popular. Este género surge a principios del $\mathrm{s}$. $X X$ en Nápoles y alcanza una gran popularidad en todo el sur de Italia.

11 Enrico Caruso fue uno de los cantantes de ópera más populares a principios del s. XX. Es considerado el primer artista en vender un millón de copias de una grabación en los primeros años de dicho siglo.

12 Cantante y actor italiano, conocido por renovar la canción tradicional napolitana y la sceneggiata.

\section{BIBLIOGRAFÍA}

Alonso, Celsa et al. (2011): Creación musical, cultura popular y construcción nacional, Madrid, ICCMU.

Brunetta, Gian Piero (1998): Storia del cinema italiano. Dal miracolo economico agli anni novanta, Roma, Editori Riuniti.

Calefato, Patricia (2000): "Tra strategie comiche e grottesche: il corpo e gli abiti nel film di Roberta Torre Tano 
da morire", Lectora: revista de dones i textualitat 5-6, 117-122.

Fraile Prieto, Teresa (2010): Música de cine en España: señas de identidad en la banda sonora contemporánea, Badajoz, Diputación de Badajoz.

Marcus, Millicent (2002): Alter Fellini. Nacional Cinema in the Postmodern Age Baltimore, The Johns Hopkins University Press.

Miscuglio, Annabella \& Daopoulo, Rony (1980): Kinomata: La donna nel cine$m a$, Bari, Dedalo libri.

Monteleone, Franco (2004): "Dal cinema in TV alla TV senza cinema", en Cinema TV. Film, televisione, video nel nuovo millenio, ed. Vito Zagarrio, Torino, Lindau, 83-91.

Mundy, John (1999): Popular Music on Screen. From Hollywood Musical to Music Video, Manchester, Manchester University Press.

Nettl, Bruno (1985): Música folklórica y tradicional de los continents occidentales, Madrid, Alianza Música.

Rodríguez Fernández, M. ${ }^{a}$ del Carmen coord. (2011): Diccionario crítico de directoras de cine europeas, Madrid, Cátedra.

Shakespeare, William (1988): Romeo y Julieta, Madrid, Cátedra.

Viñuela Suárez, Eduardo (2009): El videoclip en España (1980-1995). Gesto audiovisual, discurso y mercado, Madrid, ICCMU.

Wood, Mary P. (2005): Italian Cinema, New York, Palgrave MacMillan.

\section{FILMOGRAFÍA}

Angela (Dir. Roberta Torre, 2002).

Belleza Robada (Dir. Bernardo Bertolucci, 1996).

Bienvenidos al norte (Dany Boon, 2008).

Bienvenidos al sur (Dir. Luca Miniero, 2010).

Cinema Paradiso (Dir. Giuseppe Tornatore, 2002).

Dancer in the Dark (Dir. Lars von Trier, 1999).

El gatopardo (Dir. Lucchino Visconti, 1963).

El otro lado de la cama (Dir. Emilio Martínez Lázaro, 2002).

El Padrino (Dir. Francis Ford Coppola, 1972).
El Padrino. Parte I/ (Dir. Francis Ford Coppola, 1974).

El Padrino. Parte III (Dir. Francis Ford Coppola, 1990).

El último emperador (Dir. Bernardo Bertolucci, 1987).

Érase una vez en América (Dir. Sergio Leone, 1984).

Fiebre del sábado noche (Dir. John Badham, 1977).

I baci mai dati (Dir. Roberta Torre, 2010).

Los dos lados de la cama (Dir. Emilio Martínez Lázaro, 2005).

Los Soprano (HBO, 1999-2007).

Malena (Dir. Giuseppe Tornatore, 2000).

Mare nero (Dir. Roberta Torre, 2006).

Moulin Rouge (Dir. Baz Luhrmann, 2001).

Rocco y sus hermanos (Dir. Lucchino Visconti, 1960).

Romeo + Juliet (Dir. Baz Luhrmann, 1996).

Senso (Dir. Luchino Visconti, 1954).

Sud side story (Dir. Roberta Torre, 2000).

Tano da morire (Dir. Roberta Torre, 1997).

Uno de los nuestros (Dir. Martin Scorsese, 1990).

West Side Story (Dir. Robert Wise y Jerome Robbins, 1961). 